University of Nebraska - Lincoln

DigitalCommons@University of Nebraska - Lincoln

Si-Hwang Liou Publications

Research Papers in Physics and Astronomy

February 1987

\title{
Composition range of binary amorphous alloys
}

Sy_Hwang Liou

University of Nebraska-Lincoln, sliou@unl.edu

C.L. Chien

The Johns Hopkins University, Baltimore, Maryland

Follow this and additional works at: https://digitalcommons.unl.edu/physicsliou

Part of the Physics Commons

Liou, Sy_Hwang and Chien, C.L., "Composition range of binary amorphous alloys" (1987). Si-Hwang Liou Publications. 10.

https://digitalcommons.unl.edu/physicsliou/10

This Article is brought to you for free and open access by the Research Papers in Physics and Astronomy at DigitalCommons@University of Nebraska - Lincoln. It has been accepted for inclusion in Si-Hwang Liou Publications by an authorized administrator of DigitalCommons@University of Nebraska - Lincoln. 


\title{
Brief Reports
}

Brief Reports are short papers which report on completed research which, while meeting the usual Physical Review standards of scientific quality, does not warrant a regular article. (Addenda to papers previously published in the Physical Review by the same authors are included in Brief Reports.) A Brief Report may be no longer than $3 \frac{1}{2}$ printed pages and must be accompanied by an abstract. The same publication schedule as for regular articles is followed, and page proofs are sent to authors.

\section{Composition range of binary amorphous alloys}

\author{
S. H. Liou and C. L. Chien \\ Department of Physics and Astronomy, The Johns Hopkins University, Baltimore, Maryland 21218
}

(Received 18 September 1986)

\begin{abstract}
We have studied a number of binary metal-metal and metalloid alloy systems made by a single vapor-quench method under very consistent conditions. In each case, amorphous alloys are found in one continuous composition range $\left(x_{\min } \leq x \leq x_{\max }\right)$ regardless of the number of eutectic points in the equilibrium phase diagrams. It is found that the atomic size difference is the single most important factor in the quantitative determination of the composition range.
\end{abstract}

Through efforts spanning over two decades, amorphous alloys have been produced in many systems, but not at arbitrary compositions. ${ }^{1}$ The formation and the stability of the amorphous state are questions of fundamental and technological importance. The relevant question of interest is the stability of the amorphous state at a finite temperature. In particular, what is the concentration range or ranges in which the amorphous state exists at a finite temperature (e.g., $400 \mathrm{~K}$ )? For many years fabrication techniques have been dominated by liquid-quenching methods, such as melt spinning and splat cooling, in which generally only the eutectic compositions are quenchable. $^{1}$ In the case of transition-metal- $(T)$ metalloid $(M)$ systems, alloys of eutectic composition $T_{0.80} M_{0.20}$ (e.g., $\mathrm{Fe}_{0.80} \mathrm{~B}_{0.20}$ ) are the most well-known examples. The apparent stability of the eutectic composi- tions has prompted many theoretical predictions and models. The role of the valence-electron concentration ${ }^{2}$ and various structure models in which the smaller metalloid atoms fill up the Bernal holes ${ }^{3,4}$ have been extensively discussed.

During the last few years, various vapor-quenching methods (e.g., evaporation, sputtering ${ }^{5-8}$ ) and the newly discovered method of solid-state reaction ${ }^{9}$ have been developed or improved. These methods have inherently higher quenching rates and avoid the liquid state altogether. Consequently, the amorphous state can now be achieved in many more alloy systems with vastly extended composition ranges. $\mathrm{Fe}_{x} B_{1-x}(0 \leq x \leq 0.90), \mathrm{Fe}_{x} \mathrm{Ti}_{1-x}$ $(0.30 \leq x \leq 0.80)$, and others listed in Table $I$ are such examples. It is now clear that the eutectic compositions are only of importance to liquid-quench methods which rely

TABLE I. The constituent atomic radii $\left(r_{a}, r_{b}\right)$, ratio $(z)$, and composition range $\left(x_{\min } \leq x \leq x_{\max }\right)$ of vapor-quenched binary amorphous alloys. The theoretical predictions $\left.\left[\left(x_{\min }\right)_{t} \leq x \leq\left(x_{\max }\right)_{t}\right)\right]$ are shown in the last column.

\begin{tabular}{|c|c|c|c|c|c|c|c|}
\hline \multirow{2}{*}{$\frac{A_{x} B_{1-x}}{\mathrm{Fe}-\mathrm{Ti}}$} & \multirow{2}{*}{$\begin{array}{c}r_{A} \\
(\AA ̊ \AA)\end{array}$} & \multirow{2}{*}{$\begin{array}{c}r_{B} \\
(\AA)\end{array}$} & \multirow{2}{*}{$\frac{\frac{r_{A}}{r_{B}}=1+\delta}{1.14}$} & \multicolumn{2}{|c|}{$\begin{array}{c}\text { Experimental } \\
x_{\min } \leq x \leq x_{\max }\end{array}$} & \multicolumn{2}{|c|}{$\begin{array}{c}\text { Theory } \\
\left(x_{\min }\right)_{t} \leq x \leq\left(x_{\max }\right)_{t}\end{array}$} \\
\hline & & & & 0.30 & 0.80 & 0.28 & 0.85 \\
\hline $\mathrm{Fe}-\mathrm{Zr}$ & 1.28 & 1.58 & 1.234 & 0.20 & 0.93 & 0.19 & 0.92 \\
\hline Fe-Hf & 1.28 & 1.67 & 1.305 & 0.20 & 0.94 & 0.16 & 0.94 \\
\hline $\mathrm{Fe}-\mathrm{Ta}$ & 1.28 & 1.49 & 1.164 & 0.20 & 0.90 & 0.24 & 0.88 \\
\hline Fe-Mo & 1.28 & 1.39 & 1.086 & 0.40 & 0.80 & 0.41 & 0.75 \\
\hline $\mathrm{Fe}-\mathrm{B}$ & 1.28 & 0.78 & 0.609 & 0.0 & 0.90 & 0.03 & 0.91 \\
\hline $\mathrm{Fe}-\mathrm{Cu}$ & 1.28 & 1.27 & 1.007 & & & & \\
\hline $\mathrm{Fe}-\mathrm{Nb}$ & 1.28 & 1.46 & 1.14 & 0.25 & 0.85 & 0.27 & 0.85 \\
\hline $\mathrm{Ni}-\mathrm{Nb}$ & 1.28 & 1.46 & 1.14 & 0.20 & 0.80 & 0.27 & 0.85 \\
\hline $\mathrm{Cu}-\mathrm{Nb}$ & 1.27 & 1.46 & 1.14 & 0.20 & 0.80 & 0.26 & 0.86 \\
\hline
\end{tabular}


on the depressed melting point. The stability of an amorphous alloy has no bearing on whether it is liquidquenchable. The amorphous alloys of eutectic composition do not generally constitute systems of exceptional stability either. For example, the highest crystallization temperature of amorphous $\mathrm{Fe}_{x} \mathrm{~B}_{1-x}$ has been found at $x \simeq 0.65$ and not at $x=0.80 .^{10}$ In the case of $\mathrm{Fe}-\mathrm{Zr}$, the eutectic compositions $\left(\mathrm{Fe}_{0.91} \mathrm{Zr}_{0.09}\right.$ and $\left.\mathrm{Fe}_{0.24} \mathrm{Zr}_{0.76}\right)$, near the limits of the composition range for amorphous alloys (Table I), are essentially the least stable amorphous alloys having the lowest crystallization temperatures. Thus, the experimental results and models obtained from liquidquenched samples cannot be profitably used to address the question of composition range for amorphous alloys.

The above discussion illustrates the difficulties in addressing the problem of composition range in amorphous alloy systems. The comparisons between experimental findings and theoretical predictions are severely complicated and often misled by the fact that widely varied quenching methods (e.g., liquid quench, evaporation, sputtering) and conditions (e.g., deposition rates, substrate temperature) have been used to obtain various amorphous alloys. We have, in recent years, studied a large number of alloy systems made by a single vapor-quenching method under very consistent conditions. We have studied only binary alloys for which actual calculations can be easily performed. By varying the alloy composition we have determined, for each binary system chosen, the composition range $\left(x_{\min } \leq x \leq x_{\max }\right)$ within which the amorphous state can be formed. We show in this work that the atomic size difference is the single most important factor in the determination of the amorphous composition range $\left(x_{\min } \leq x \leq x_{\max }\right)$. The values of $x_{\min }$ and $x_{\max }$ are shown to depend primarily on the atomic sizes of the constituent elements. Simple formulas provide excellent approximations for the prediction of the composition range of the amorphous alloys.

All of our samples, $6-24 \mu \mathrm{m}$ thick, were deposited on liquid-nitrogen-cooled substrates by a high-rate sputtering device using homogeneously mixed composite targets. ${ }^{5,6}$ The composition ranges of the amorphous alloys, listed in Table I, are those for which the crystallization temperature is at least $400 \mathrm{~K}$, which serves as an operational criterion. Obviously, the range would be smaller or larger if a higher or lower temperature were chosen. The composition range was determined by $\mathrm{x}$-ray diffraction and complemented by Mössbauer spectroscopy, magnetic measurement, and other techniques which are sensitive to structure. As an example, x-ray diffraction and Mössbauer spectroscopy results for vapor-quenched $\mathrm{Fe}-\mathrm{Ti}$ alloys within 1 at. $\%$ of $x_{\max }=0.80$ are shown in Fig. 1. The sample of $\mathrm{Fe}_{0.82} \mathrm{Ti}_{0.18}$ is crystalline bcc and strongly ferromagnetic, $\mathrm{Fe}_{0.80} \mathrm{Ti}_{0.20}$ is amorphous and not magnetic at $300 \mathrm{~K}$, and $\mathrm{Fe}_{0.81} \mathrm{Ti}_{0.19}$ is found to be a mixture of the two phases. The value of $x_{\min }$ is less accurately known than that of $x_{\max }$. Since the samples were prepared in steps of 5 at. $\%$, the actual value of $x_{\min }$ in some systems could be up to 5 at. \% less than that listed in Table I. The composition ranges of some of these vapor-quenched alloy systems have also been studied by other researchers with good general agreement. ${ }^{7,8}$ The differences are probably a reflection of the fabrication conditions, such as substrate temperature.

As shown in Table I, vapor-quenched amorphous alloys exist in very wide composition ranges which encompass all the liquid-quenchable compositions and those made by solid-state reaction. In each system, there is a single continuous composition range for the amorphous state, regardless of whether there is one eutectic point (e.g., Fe-B) or two (e.g., Fe-Zr) in the phase diagram. ${ }^{11}$ It is noted that the width of the composition range $\left(x_{\max }-x_{\min }\right)$ of the amorphous state of each alloy system is closely correlated with the size difference of the constituent atomic species. As will be shown below, the expressions that
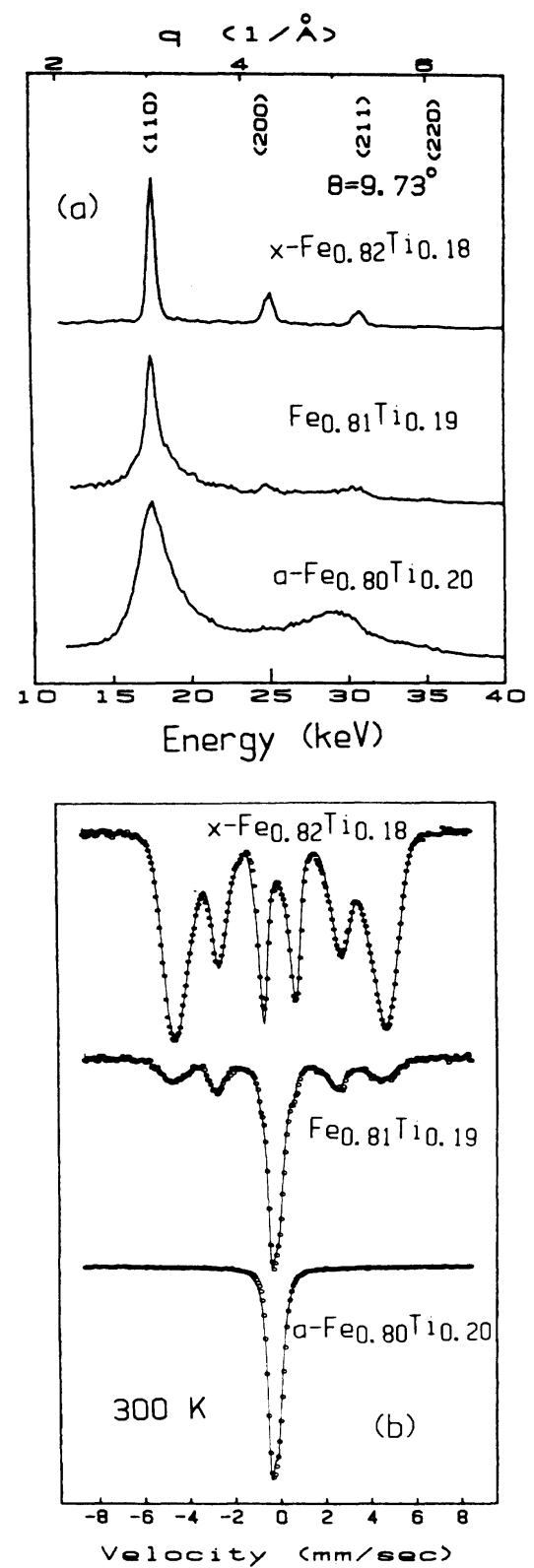

FIG. 1. (a) Energy dispersive x-ray diffraction and (b) Mössbauer spectra at $300 \mathrm{~K}$ of vapor-quenched $\mathrm{Fe}-\mathrm{Ti}$ alloys near $x_{\max }=0.80$. 
quantitatively describe the experimental results for an amorphous alloy system of the form $A_{x} B_{1-x}$ are

$$
\begin{aligned}
& \left(x_{\text {max }}\right)_{t} \simeq 1-2 \lambda_{1} \frac{V_{A}}{|\Delta V|}, \\
& \left(x_{\text {min }}\right)_{t} \simeq 2 \lambda_{1} \frac{V_{B}}{|\Delta V|},
\end{aligned}
$$

where $V_{A}$ and $V_{B}$ are the atomic volumes, $|\Delta V|=\left|V_{A}-V_{B}\right|$, and $\lambda_{1}$ is a parameter. These two expressions depend only on the geometrical factors of the atomic species.

Egami and Waseda recently developed an atomic scale elasticity theory which led to the stress criteria for the topological instability of a solid solution. ${ }^{12}$ According to this model, the amorphous alloys are stabilized because the solid solutions of the corresponding compositions are topologically unstable. For an alloy system of $A_{x} B_{1-x}$, the minimum solute concentration necessary to obtain a stable amorphous phase by rapid quenching has been indicated to be

$$
x_{t}=\frac{1}{1-y+\frac{y}{\lambda_{1}}\left[1-\left(\frac{2}{1+z}\right)^{3}\right]}
$$

where $z=r_{B} / r_{A}=1+\delta$ is the ratio of the atomic radii, and

$$
y=z^{3}\left[\frac{2}{3}\left[\frac{2}{1+z}\right]^{3}+\frac{1}{3}\right]
$$

is the volume ratio of deformed $A$ and $B$ atoms and $\lambda_{1}$ is a parameter to be determined. Because of the small values of $\delta$ and $\lambda_{1}$, which is of the order of $0.05, x_{t}$ can be approximated as

$$
x_{t} \simeq \frac{\lambda_{1}}{y}\left[1-\left(\frac{2}{1+z}\right]^{3}\right] \simeq 2 \frac{\lambda_{1}}{z^{3}-1}\left[1+O\left(\delta^{2}\right)\right]
$$

after simple manipulations. Since $z^{3}=V_{B} / V_{A}$ is the atomic volume ratio, Eq. (5) leads to Eqs. (1) and (2), accurate to order $O\left(\delta^{2}\right)$.

The validity of Eqs. (1) and (2) and the value of the parameter $2 \lambda_{1}$ can be evaluated by fitting our experimentally determined values of $x_{\min }$ and $x_{\max }$ to the theoretical values of $\left(x_{\min }\right)_{t}$ and $\left(x_{\max }\right)_{t}$. In Fig. 2 we show the plots of $1-x_{\max }$ versus $V_{A} /|\Delta V|$ and $x_{\min }$ versus $V_{B} /|\Delta V|$. A slope of $2 \lambda_{1}=0.07$ provides a good fit in both cases but the fit can be slightly improved in $x_{\min }$ by using $2 \lambda_{1}=0.09$. Given the uncertainty in $x_{\min }$ and the likelihood that, as mentioned above, the actual value may be slightly smaller, a single value of $2 \lambda_{1}=0.07$ should suffice. We list in the last column of Table $I$ the calculated values of $\left(x_{\min }\right)_{t}$ and $\left(x_{\max }\right)_{t}$ using $2 \lambda_{1}=0.09$ and 0.07 , respectively. The agreement between the experimental results and the theoretical predictions is remarkable. We know of no other theoretical models which achieve comparable success. In the series of Fe-based amorphous alloys, good agreements are obtained for larger as well as smaller alloying elements, and for both metal-metal systems and metal-metalloid systems. In the case of $\mathrm{Fe}-\mathrm{B}$, the amorphous state can actually be extended to pure B, further than predicted. This is due to the covalent bonding which has not been included in the model. Similar situations occur in amorphous alloys based on $\mathrm{Si}$ and Ge. ${ }^{13}$

It should be emphasized that although only atomic sizes appear in Eqs. (1) and (2), effects far beyond geometrical differences are indirectly incorporated. This is because the atomic size difference is intimately related to the heat of formation, ${ }^{14}$ the electronic structure, ${ }^{2}$ the competing equilibrium crystal structures, ${ }^{15}$ etc., all of which are known to be important in the stability of the amorphous state. However, these models have not been able to successfully predict the composition range of the amorphous alloys, to a degree comparable with the present model. For example, the heat of formation of amorphous alloys (for that matter, crystalline alloys as well) is generally large and negative. But there are many exceptions in which the heat of formation is only slightly negative or even positive. ${ }^{12}$

The importance of the atomic size difference has been recognized previously. It has been empirically found that for most liquid-quenched samples the atomic sizes differ by at least $10 \%$, i.e., the $10 \%$ size difference rule. ${ }^{16}$ However, this rule does not address the composition-range question. As a matter of fact, one can use the present
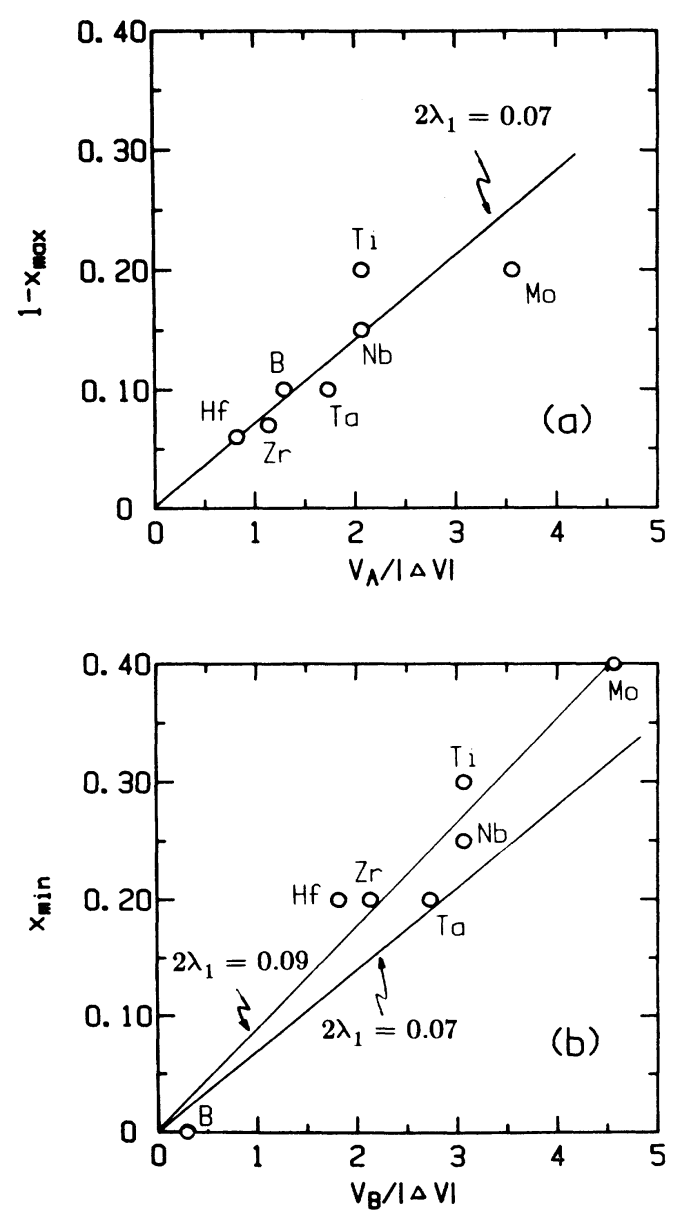

FIG. 2. (a) $1-x_{\max }$ vs $V_{A} /|\Delta V|$; (b) $x_{\min }$ vs $V_{B} /|\Delta V|$ of a number of amorphous $A_{x} B_{1-x}$ alloy systems (see text). 
model to reexamine the minimum size difference below which no amorphous alloy exists. From Eqs. (1) and (2), one obtains $|\Delta V| \geq 2 \lambda_{1}\left(V_{A}+V_{B}\right)$. Using $2 \lambda_{1}=0.07$ one has $\left(V_{A} / V_{B}\right)_{\min } \simeq 1.15$, or $\left(r_{A} / r_{B}\right)_{\min } \simeq 1.05$. Therefore, the often quoted $10 \%$ difference rule from liquid quenching should be relaxed to 5\%. Experimentally, as shown in Table $\mathrm{I}$, this is confirmed in Fe-Mo where $r_{A} / r_{B}$ is only 1.086 and amorphous alloys do exist in an extended composition range. On the other hand, in the case of $\mathrm{Fe}-\mathrm{Cu}$, the atomic size difference is practically zero. Indeed, experimentally we have found no amorphous alloy at any composition. Vapor-quenched $\mathrm{Fe}_{x} \mathrm{Cu}_{1-x}$ alloys consist only of new metastable crystalline alloys, bcc $(x \geq 0.70)$ or fcc $(x \leqslant 0.70)$, over the entire composition range. ${ }^{17}$ Similar examples are found in vapor-quenched $\mathrm{Fe}-\mathrm{Ni}$ and $\mathrm{Fe}-$ Mn alloys, all of which are crystalline alloys. ${ }^{8}$

It should be mentioned that atomic sizes have been known to play an important role in substitutional crystalline alloys. For example, one of the Hume-Rothery rules is on the atomic size difference and one of the coordinates of the Darken-Gurry maps is atomic size. ${ }^{18}$ However, several distinctions should be made. The solubility range of crystalline alloys does not generally correlate with the composition range of the amorphous alloys. In the cases of Fe-based alloys studied here, amorphous alloys of extensive composition ranges can be achieved regardless of whether the solubility in crystalline alloys is low (e.g., B, $\mathrm{Hf}$ in $\mathrm{Fe}$ ), or extensive (e.g., $\mathrm{Si}, \mathrm{Mo}$ in $\mathrm{Fe}$ ). ${ }^{19}$ In other cases, for either high (e.g., $\mathrm{Fe}-\mathrm{Ni}$ alloys) or low (e.g., $\mathrm{Fe}-$ $\mathrm{Cu}$ alloys) solubility in the crystalline alloys, no amorphous alloy can be found. Indeed, many factors have to be included to account for the solubility of crystalline alloys. In amorphous alloys, however, the atomic size difference appears to be the dominant factor.

In conclusion, we show in this work that the atomic size difference is the single most important factor in determining the composition range of amorphous alloys. The remarkably simple expressions which depend only on atomic volumes provide very good agreements with the experimental results. It serves as an excellent first approximation for the quantitative prediction of the composition range of binary amorphous alloys. There is no discernible difference found between metal-metalloid and metal-metal amorphous alloys.

This work is supported by National Science Foundation Grant No. DMR-86-07150. We thank Professor T. Egami for useful discussions.
${ }^{1}$ E.g., H. S. Chen, Rep. Prog. Phys. 43, 353 (1980); Amorphous Metallic Alloys, edited by F. E. Luborsky (Butterworth, London, 1983).

${ }^{2}$ S. R. Nagel and J. Tauc, Phys. Rev. Lett. 35, 380 (1975).

${ }^{3}$ D. E. Polk, Scr. Metall. 4, 117 (1970).

${ }^{4}$ J. D. Bernal, Proc. R. Soc. London, Ser. A 280, 299 (1964).

${ }^{5}$ C. L. Chien and K. M. Unruh, Phys. Rev. B 25, 5790 (1982).

${ }^{6}$ S. H. Liou and C. L. Chien, J. Appl. Phys. 55, 1820 (1984).

${ }^{7}$ K. Fukamichi and R. J. Gambino, IEEE Trans. Magn. MAG17, 3059 (1981).

${ }^{8}$ K. Sumiyama and Y. Nakamura, J. Magn. Magn. Mater. 35, 219 (1983).

${ }^{9}$ R. B. Schwartz and W. L. Johnson, Phys. Rev. Lett. 51, 415 (1983).

${ }^{10}$ F. Kanamaru, S. Miyazaki, M. Shimada, M. Koizumi, K. Oda, and Y. Mimura, J. Solid State Chem. 49, 1 (1983).

${ }^{11} \mathrm{O}$. Kubaschewski, Iron Binary Phase Diagrams (SpringerVerlag, Berlin, 1982).
${ }^{12}$ T. Egami and Y. Waseda, J. Non-Cryst. Solids 64, 113 (1984).

${ }^{13}$ G. Marchal, Ph. Mangin, M. Piecuch, Chr. Janot, and J. Hubsoh, J. Phys. F 7, L165 (1977).

${ }^{14}$ A. R. Miedema, Z. Metallk. 70, 345 (1979).

${ }^{15}$ B. Liu, W. L. Johnson, M.-A. Nicolet, and S. S. Lau, Appl. Phys. Lett. 42, 45 (1983).

${ }^{16}$ E.g., B. C. Giessen, in Proceedings of the 4th International Conference on Rapidly Quenched Metals, edited by $\mathrm{T}$. Masumoto and K. Suzuki, (Jap. Inst. Metals, 1982), Vol. 1, p. 213.

${ }^{17}$ C. L. Chien, S. H. Liou, D. K. Kofalt, W. Yu, T. Egami, and T. R. McGuire, Phys. Rev. B 33, 3247 (1986).

${ }^{18}$ E.g., Theory of Alloy Phase Formation, edited by L. H. Bennett (Metallurgical Society of AIME, New York, 1980).

${ }^{19}$ W. G. Moffat, The Handbook of Binary Phase Diagrams (General Electric, Schenectady, New York, 1978), Vols. 1, 2, and 3. 